\title{
CYP-Dependent Metabolism of PF9601N, A New Monoamine Oxidase- B Inhibitor, by C57BL / 6 Mouse and Human Liver Microsomes
}

\author{
Stefania Dragoni ${ }^{1}$, Giada Materozzi ${ }^{1}$, Federica Pessina ${ }^{1}$, Maria Frosini ${ }^{1}$, José Luis Marco ${ }^{2}$, Mercedes \\ Unzeta $^{3}$, Giampietro Sgaragli ${ }^{1}$ and Massimo Valoti ${ }^{1}$ \\ ${ }^{1}$ Dipartimento di Scienze Biomediche, Sezione di Farmacologia, Fisiologia e Tossicologia, Università di Siena, Italy, \\ ${ }^{2}$ Laboratorio de Radicales Libres, Instituto de Chimica Organica General, CSIC, Madrid, ${ }^{3}$ Departamento of \\ Bioquimica i Biologia Molecular, Universitat Autonoma de Barcelona, Spain
}

Received June 21, 2007; Revised, September 20, 2007; Accepted, October 4, 2007; Published October 8, 2007.

\begin{abstract}
Purpose. The selective monoamine oxidase-B (MAO-B) inhibitor, ldeprenyl, is still used for treating Parkinson's patients, however, a disadvantage of its use lies in the formation of $l$-amphetamine and $l$ methamphetamine. Subsequently, this has promoted the design of a novel, more potent, MAO-B inhibitor PF9601N, which also has neuroprotective and antioxidant properties. The aim of this work was to investigate the effect of treatment with PF9601N on its own phase I hepatic metabolism. Kinetic parameters of PF9601N CYP-dependent N-dealkylation reaction was also studied and compared with those of l-deprenyl. Methods. C57BL/6 mice were treated with PF9601N for 4 days. After CYP content and related monooxygenase activities were assayed in liver microsomes of control and treated animals. Results. CYP activities, cytochrome $b_{5}$ content, NADPH-cytochrome $\mathrm{P} 450$ reductase and various monooxygenase activities were unaffected by in vivo PF9601N treatment. With microsomes from both control and treated mice, the PF9601N-dealkylation product, FA72, was the only detected metabolite with its formation rate following an hyperbolic, Michaelis-Menten curve. Among various inhibitors, only ketoconazole inhibited the FA72 formation rate, indicating a major involvement for CYP3A. Apparent $\mathrm{Km}$ and Vmax values generated by human liver microsomes were similar to those found with mouse microsomes. Ketoconazole inhibition indicates that CYP3A is one of the major enzymes involved in PF9601N metabolism also by human liver microsomes. In mouse liver microsomes, the intrinsic clearance of PF9601N was significantly lower than that of $l$ deprenyl suggestive of an improved bioavailability for the former. Conclusion. The observed favourable metabolic profile may suggest suitability of PF9601N for clinical use.
\end{abstract}

\section{INTRODUCTION}

l-Deprenyl is a selective monoamine oxidase-B (MAO-B) inhibitor. Owing to its capacity to increase striatal dopamine levels, it has been used for treating Parkinson's patients (1). In patients with early, untreated Parkinson's disease, controlled clinical trials have demonstrated that $l$ deprenyl delays the disability and decrease the rate of progression of signs and symptoms of this condition (2).

l-Deprenyl undergoes $90 \%$ presystemic clearance, hence, its bioavailability is low (3). In addition the observation that pretreating animals with l-deprenyl protects them against the neurotoxic effects of compounds such as 1methyl-4-phenyl-1,2,3,6-tetrahydropyridine

(MPTP), 6-hydroxydopamine and N-(2chloroethyl)-N-ethyl-2-bromobenzylamine (DSP4) has stimulated studies aimed at clarifying the pharmacological and biochemical properties of this drug (4). Although other MAO-B inhibitors also act as neuroprotectors in experimental models of parkinsonism at concentrations lower than those required for MAO-B inhibition (5), $l$ deprenyl is the only MAO-B inhibitor available for therapeutic use. Its metabolites include $l$ amphetamine and $l$-methamphetamine, which can have adverse side-effects, and for some years, there has been some controversy as to whether $l$ deprenyl should continue to be part of Deprenyl and Tocopherol Antioxidative Therapy for Parkinson's (DATATOP) treatment (6).

Corresponding Author: Prof Massimo Valoti, Dipartimento di Scienze Biomediche, School of Pharmacy, Siena, Italy, E-mail: valoti@unisi.it 
Therefore, the search for new MAO-B inhibitors without potential amphetamine-like properties is a matter of great therapeutic interest. N-(2propynyl)-2-(5-benzyloxy-indolyl) methylamine, or PF $9601 \mathrm{~N}$, has been synthesized in the Laboratorio de Radicales Libres (Instituto de Chimica Organica General, CSIC, Madrid, Spain) by Cruces et al. (7). It has been shown to behave in vitro as a suicide MAO-B inhibitor (8), so that its effect could only be overcome by de novo MAO-B synthesis. It has also been shown that this novel MAO-B inhibitor easily crosses the blood-brain-barrier and results in in vivo, properties similar to those described in vitro (8).

Furthermore, PF9601N blocks dopamine uptake in human caudate and rat synaptosomal fractions with similar potency to that of $l$ deprenyl (8), whereas rasagiline does not (9). PF $9601 \mathrm{~N}$ also enhanced the duration of L-DOPAinduced controlateral turning in 6hydroxydopamine (6-OHDA) lesioned rats (10).

In a recent study (11) it has been shown that PF9601N and its putative cytochrome P450dependent metabolite, 2-(5-benzyloxy-indolyl) methylamine (FA72) (figure 1) exerted antioxidant and neuroprotective activities in human neuroblastoma SHSY5Y cell line injured by dopamine oxidative stress. The concomitant structure-activity relationship study allowed us to conclude that the presence of a benzyloxy-, or a hydroxy- or methoxy- group in 5- position of the indol ring enhanced its antioxidant features, showing an increasing order of antioxidant activity for the primary $>$ secondary $>$ tertiary amine (11).

Due to the possible relevant pharmacological properties of the cytochrome P450 (CYP)-dependent metabolites of PF9601N, a study was performed in order to clarify the metabolism of this MAO-B inhibitor and envisage any interactions with other drugs at CYP system level. The effects on liver CYP isozymes of pretreating animals with PF9601N were investigated on C57BL/6 mice, a widely accepted rodent model for Parkinsonism induced with MPTP. The present results indicate that PF9601N does not impair monoxygenase activities and has a lower intrinsic clearance as compared to l-deprenyl, thus suggesting that its use in Parkinson's patients is devoid of some of $l$-deprenyl disadvantages.

\section{METHODS}

\section{Materials}

Human pooled liver microsomes were purchased from SIGMA Chemical Co (Milan, Italy), N-(2propynyl)-2-(5-benzyloxy-indolyl) methylamine (PF $\quad 9601 \mathrm{~N}), \quad 2-(5-$ benzyloxy-indolyl) methylamine (FA72) and N-(2-butynyl)-2-(5benzyloxy-indolyl) methylamine (FA 74) were synthesized in Laboratorio de Radicales Libres (Instituto de Chimica Organica General, CSIC, Madrid) (7), L-(-)-N, $\alpha$-dimethyl-N-2propynylphenethyl-amine hydrochloride (ldeprenyl-HCl) and L-(-)-N, $\alpha$-methyl-N-2propynylphenethyl-amine (l-nordeprenyl) were gifts from Chinoin Chemical Works (Budapest, Hungary), ketoconazole from Jannsen (Roma, Italy); NADPH, NADP, and glucose-6-phosphate dehydrogenase were provided by Boehringer (Mannheim, Germany). All other chemicals and solvents were of the highest grade available and obtained from common commercial sources.

\section{Drug treatments}

The animal protocols used were reviewed and approved by the Animal Care and Ethics Committee of the Università degli Studi di Siena and Ministry of Health, Rome, Italy. Male C57BL/6 mice (20-25 g body weight), obtained from Charles River (Milan, Italy), were housed in standard cages in a temperature- and lightcontrolled facility and allowed free access to food (M.I.L. from Morini, S.Polo d'Enza, Italy) and water. After an acclimatisation period of 10 days, one group of 10 mice was treated daily i.p with PF9601N $10 \mathrm{mg} \mathrm{x} \mathrm{Kg}^{-1}$ in normal saline and DMSO (9:1) for 4 days, as reported for l-deprenyl study in Valoti et al. (12). The control group consisted of 10 mice treated i.p with vehicle (saline: DMSO, 9:1).

\section{Preparation of liver microsomes}

All mice were fasted overnight prior to the sacrifice by $\mathrm{CO}_{2}$ asphyxia. The abdominal cavity was opened and the liver perfused in situ, through the vena cava, with ice-cold physiological saline solution. Livers were excised and weighed. They were then combined in pairs, chopped, suspended in 4 volumes of $0.25 \mathrm{M}$ sucrose and homogenized in a Potter-Elvejhem homogeniser fitted with a teflon pestle. Homogenates were centrifuged at 
$10,000 \mathrm{~g}$ for $20 \mathrm{~min}$ and the resulting supernatants were centrifuged at $105,000 \mathrm{~g}$ for $1 \mathrm{~h}$. The resulting microsomal pellets were suspended in $0.01 \mathrm{M}$ Tris- $\mathrm{HCl}$ buffer, $\mathrm{pH} 7.6$, containing 151 $\mathrm{mM} \mathrm{KCl}, 1 \mathrm{mM}$ EDTA and $20 \%$ glycerol, and stored in liquid nitrogen until use.

\section{Assay procedures}

CYP and cytochrome $b_{5}$ contents were measured from the CO-difference spectra of the microsomal preparation by the method of Omura and Sato (13) at A: $450-490 \mathrm{~nm}(\varepsilon: 91 \mathrm{mM})$ and A:424-490 $\mathrm{nm}(\varepsilon: 112 \mathrm{mM})$, respectively. The minimum amount of CYP and cytochrome $b_{5}$ detectable was $0.05 \mathrm{nmolesxmg}^{-1}$ protein (CV $7.4 \%$ ) and $0.07 \mathrm{nmolesxmg}^{-1}$ protein (CV 6.3\%), respectively. NADPH-cytochrome $\mathrm{P} 450$ reductase activity was measured by following the cytochrome c reduction at $550 \mathrm{~nm}$ according to Masters et al. (14). The minimal amount detectable was 1 nmolxmin ${ }^{-1} \mathrm{xmg}^{-1}$ protein (CV $5.6 \%$ ). Testosterone hydroxylase activity was determined by an HPLC method (15) after $30 \mathrm{~min}$ microsomes incubation in presence of $0.2 \mathrm{mM}$ testosterone, minimal amount detectable was 2 pmolxmin $^{-1} \mathrm{xmg}^{-1}$ protein (CV $8.3 \%$ \%).
Erythromycin demethylase (ErD) was assayed by following the formation of formaldehyde, trapped with the semicarbazide and measured with the Nash reagent at $412 \mathrm{~nm}$, minimal amount detectable was 50 pmolx min $^{-1} \mathrm{xmg}^{-1}$ protein $(\mathrm{CV}$ 9.7\%). Methoxyresorufin O-demethylase (MROD), ethoxyresorufin O-deethylase (EROD), pentoxyresorufin O-depentylase (PROD) and benzyloxyresorufin O-debenzylase (BROD) activities were determined by measuring the formation of the fluorescence product resorufin at excitation and emission wavelenght of 522 and $586 \mathrm{~nm}$, respectively (17). The minimum amount detectable was 0.2 pmolxmin $^{-1} \mathrm{xmg}^{-1}$ protein (CV\% 3.6). Coumarin hydroxylase activity $(\mathrm{CoH})$ was determined by measuring the fluorescence of 7-OH-coumarin at excitation and emission wavelength of 370 and $450 \mathrm{~nm}$, respectively as reported by Ko et al. (18). The minimum amount of compound detectable was 1.2 pmolxmg $^{-1}$ protein (CV6.8\%). $p$-Nitrophenol (pNPH) hydroxylase activity was assayed by recording after $30 \mathrm{~min}$ period the formation of $\mathrm{p}$ nitrocatechol according to the procedure describe by Reinke and Moyer (19). The minimum amount detectable was $0.1 \mathrm{nmolxmin}{ }^{-1} \mathrm{xmg}^{-1}$ protein $(\mathrm{CV}$ $8.1 \%$ ).

A)<smiles>C#CNCc1cc2cc(OCc3ccccc3)ccc2[nH]1</smiles>

PF9601N

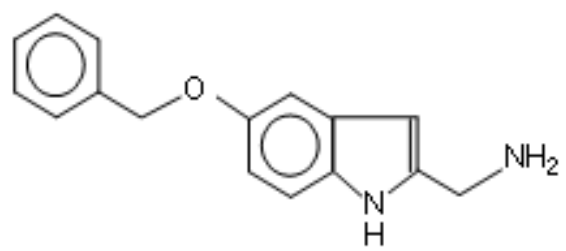

FA72

B)

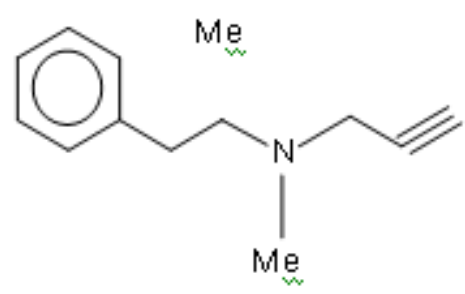

l-DEPRENYI

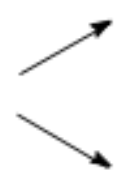

NORDEPRENYL

Figure 1. CYP-dependent N-dealkylation of PF9601N (panel A) and l-deprenyl (panel B). 


\section{Ex vivo and in vitro PF9601N metabolism}

To investigate PF9601N N-dealkylation reaction, incubation mixture consisted of $0.5 \mathrm{mg} \mathrm{x} \mathrm{ml}^{-1}$ of liver microsomal protein, a range concentration of PF9601N (3-300 $\mu \mathrm{M})$ and $100 \mathrm{mM}$ phosphate buffer, $\mathrm{pH} 7.4$, in a final volume of $0.5 \mathrm{ml}$. The reaction was started by adding $100 \mu \mathrm{l}$ of a solution (NADPH-generating system) containing $1 \mathrm{mM} \mathrm{NADP}^{+}, 4 \mathrm{mM}$ glucose-6-phosphate and $1 \mathrm{U}$ $\mathrm{x} \mathrm{ml}^{-1}$ glucose-6-phosphate-dehydrogenase in 48 $\mathrm{mM} \mathrm{MgCl} 2$. After 30 min incubation in a shaking water bath thermostatted at $37^{\circ} \mathrm{C}$, the reaction was terminated by adding $0.1 \mathrm{ml}$ of $5 \mathrm{M} \mathrm{NaOH}$ and cooled in ice-bath. Blanks containing boiled microsomes were incubated under the same conditions as the drug.

The PF9601N N-dealkylation reaction by human liver microsomes was carried out as above, by extending the reaction up to $60 \mathrm{~min}$. Reaction mixtures were spiked with $100 \mathrm{nmol}$ FA74 as internal standard and extracted once with $6 \mathrm{ml}$ ethylacetate. The recovery of both parent drug and metabolites was subsequently determined by HPLC.

\section{HPLC analysis}

HPLC analysis was performed on a Shimadzu LC-10AD liquid chromatograph equipped with a EC150/4,6 Nucleosil 100 C18 $(150 \times 4.6 \mathrm{~mm}, 5$ $\mu \mathrm{m})$ capillary column at a flow rate of $1 \mathrm{ml} \mathrm{x} \mathrm{min}^{-}$ 1. The mobile phase consisted of $10 \mathrm{mM}$ $\mathrm{KH}_{2} \mathrm{PO}_{4} / \mathrm{CH}_{3} \mathrm{CN} / \mathrm{CH}_{3} \mathrm{OH} \quad(60: 35: 5), \quad \mathrm{pH} 2$. Ultraviolet detector (Shimadzu LC-10AV6) was set at $270 \mathrm{~nm}$. The sample was injected by means of a reodyne valve with a $20 \mu 1$ loop. Calibration curves were obtained by adding different amounts of the analytes to heat-inactivated microsomes.

Under the conditions described above retention times for $P F 9601 \mathrm{~N}$ and its Ndepropynylated metabolite, FA72, were 7.8 and 5.5 min, respectively. The internal standard FA74 presented a peak at $10.1 \mathrm{~min}$. The recovery of analytes after incubation was $85 \%$ for PF9601N, $78 \%$ for FA72 and $80 \%$ for FA74. The sensitivity limit of the method, taken as the ratio between peak height of compounds and the background noise height $\geq 10$ was $1.26 \mathrm{nmol}$ injected. The relationship between analytes concentration and peak areas ratio versus area of the internal standard was linear up to $100 \mu \mathrm{M}$ of the metabolite and $300 \mu \mathrm{M}$ of the parent compound solution. Analysis of 6 standard curves performed over a week gave a correlation coefficient $\left(\mathrm{r}^{2}\right)$ 0.9625 . Day by day, the coefficient of variation of the slope of the calibration curves was $7.6 \%$.

\section{In vitro l-deprenyl metabolism}

When l-deprenyl was used as a substrate the incubation mixture consisted of $0.5 \mathrm{mg} \mathrm{x} \mathrm{ml}^{-1}$ of mouse liver microsomal protein, a range concentration of $l$-deprenyl $(3-300 \mu \mathrm{M})$ and 100 $\mathrm{mM}$ phosphate buffer, $\mathrm{pH} 7.4$, in a final volume of $1 \mathrm{ml}$. The reaction was started by adding 100 $\mu \mathrm{l}$ of NADPH-GS solution. After $15 \mathrm{~min}$ incubation in a shaking water bath thermostatted at $37^{\circ} \mathrm{C}$, the reaction was stopped by adding 0.2 $\mathrm{ml}$ of $5 \mathrm{M} \mathrm{NaOH}$ and cooling in ice-bath. Blanks containing boiled microsomes were incubated under the same conditions as the drug incubations. The metabolites and parent compounds were determined by GLC analysis, as reported elsewhere (20). The sensitivity limit of the method, taken as the ratio between peak height of compounds and the background noise height $\geq 10$ for the parent compound and the metabolites was 5 pmol injected, day by day, the $\mathrm{CV} \%$ of the slope of the calibration curves (range $0.05-100 \mu \mathrm{M})$ was $3 \%$ for $l$-deprenyl, $12 \%$ methamphetamine and $8.5 \%$ for nordeprenyl.

\section{In vitro inhibition of PF9601N metabolism by mouse and human liver microsomes}

Inhibition experiments were carried out by incubating mouse liver microsomal preparations $(\mathrm{n}=5)$ with $50 \mu \mathrm{M}$ inhibitors ( $\alpha$-naphthoflavone, 8 methoxypsoralen, sulfaphenazole, quinidine, 4methylpyrazole, ketoconazole and secobarbital) (21-26), considered to be relatively specific for some CYP enzymes (CYPs 1A, 2A6, 2C9, 2D6, $2 \mathrm{E} 1,3 \mathrm{~A} 4$ in human and 2B1 in rat, respectively). Inhibition rates were assessed at $80 \mu \mathrm{M}$ PF9601N. The reaction mixture contained 0.5 or $1 \mathrm{mg} \mathrm{x} \mathrm{ml}^{-1}$ of mouse or human microsomal protein, respectively, $50 \mu \mathrm{M}$ inhibitor and $100 \mathrm{mM}$ phosphate buffer, $\mathrm{pH}$ 7.4. The inhibitor was added first to microsomes and preincubated for $5 \mathrm{~min}$, the reaction was started with PF9601N and $100 \mu \mathrm{l}$ NADPH-GS in a shaking water bath thermostatted at $37^{\circ} \mathrm{C}$. The reaction was stopped after $30 \mathrm{~min}$ incubation, for mouse, and $1 \mathrm{~h}$ for human microsomes by adding $0.2 \mathrm{ml}$ of $5 \mathrm{M}$ $\mathrm{NaOH}$. 


\section{Statistical analysis}

Kinetic parameters were calculated according to the Michaelis-Menten equation for one or two enzymes by nonlinear regression analysis (Prism 3.02 Graphpad Software Inc, San Diego, CA, USA). All values are presented as means \pm standard error of the mean (S.E.M.). The significance of differences between treatment and control groups was established by the Student's $t$ test.

\section{RESULTS}

Mixed function oxidase activities in liver microsomes from $\mathrm{C} 57 \mathrm{BL} / 6$ control and treated mice

The 4-days treatment with PF9601N did not significantly alter either body or liver weight gain (results not shown). CYPs and cytochrome $b_{5}$, NADPH-cytochrome P450 reductase and several monooxygenase activities in liver microsomes from control and treated mice are given in Table 1. Either CYP and cytochrome b5 content or NADPH-cytochrome P-450 reductase activity turned out to be unaffected by treatment. Furthermore, CYP related activities namely pNPH (CYP2E1), CoH (CYP2A5), EROD (CYP1A1), MROD (CYP1A2), PROD (CYP2B) ErD (CYP3A) were not significantly changed by treatment.

\section{Kinetics analysis of PF9601N CYP-dependent $\mathrm{N}$-dealkylation by C57BL/6 mice and human liver microsomes}

A typical chromatogram of PF9601N after $30 \mathrm{~min}$ incubation with mice liver microsomes is reported in Figure 2. FA72 appeared to be the only detectable metabolite of PF9601N under our experimental conditions. Furthermore, two additional unknown peaks, with retention time of 2.9 and $3.7 \mathrm{~min}$, respectively, were evident. However, they were not related to PF9601N CYP-dependent metabolism, since they were present also in the blank samples. CYP-dependent $\mathrm{N}$-dealkylation of PF9601N under the conditions described above was linear with time, up to 60 min, both in mice and in human microsomal preparations; initial rates being proportional to the amount of protein added up to $2 \mathrm{mg} \mathrm{x} \mathrm{ml}^{-1}$.

When PF9601N was incubated with liver microsomal fractions prepared either from control and treated animals, at all substrate concentrations tested, FA72 turned out to be the only detected metabolite, the reaction following a hyperbolic, Michaelis-Menten equation thus suggesting that only one CYP isozyme is involved in PF9601N metabolism. In conjunction with these observations (Figure 3 inset), linear EadieHofstee plots (27) were obtained. Similar results were observed when kinetic analyses were performed with microsomes from in vivo PF9601N-treated mice (Figure 3). These microsomes, showed lower though not significant Vmax and $\mathrm{Km}$ values as compared to those observed in control preparations. Relative $\mathrm{Vmax} / \mathrm{Km}$ ratios, taken as an index of intrinsic clearance, were of the same order of magnitude in either preparations (Table 2).

When PF9601N was incubated with human microsomes FA72 formation rate followed a single-substrate kinetic, as shown in Figure 4. The apparent $\mathrm{Km}$ and Vmax values were of the same order of magnitude as those observed with mouse microsomes (Table 2).

Table 1. Mixed function oxidase activities in liver microsomes from $\mathrm{C} 57 \mathrm{BL} / 6$ mice treated with vehicle (Control) or PF9601N $10 \mathrm{mg} \mathrm{x} \mathrm{Kg}^{-1}$ i.p (Treated) for 4 days.

\begin{tabular}{lll}
$\begin{array}{l}\text { Enzyme } \\
\text { Content/Activity* }\end{array}$ & Control & Treated \\
\hline Cytochrome-P450 & $0.794 \pm 0.069$ & $0.707 \pm 0.059$ \\
Cytochrome $b_{5}$ & $0.654 \pm 0.080$ & $0.653 \pm 0.040$ \\
NADPH-P450 reductase & $124.085 \pm 20.632$ & $151.621 \pm 34.260$ \\
$\mathrm{pNPH}$ & $2.129 \pm 0.558$ & $2.095 \pm 0.366$ \\
$\mathrm{CoH}$ & $0.045 \pm 0.008$ & $0.042 \pm 0.007$ \\
EROD & $0.025 \pm 0.004$ & $0.024 \pm 0.005$ \\
$\mathrm{MROD}$ & $0.094 \pm 0.017$ & $0.075 \pm 0.013$ \\
$\mathrm{PROD}$ & $0.0105 \pm 0.001$ & $0.017 \pm 0.006$ \\
$\mathrm{BROD}$ & $0.075 \pm 0.002$ & $0.084 \pm 0.003$ \\
ErD & $0.544 \pm 0.102$ & $0.591 \pm 0.154$ \\
\hline
\end{tabular}

* Content and activity were expressed as nmol $\mathrm{x} \mathrm{mg}^{-1}$ protein and nmol $\times$ min $^{-1} \times \mathrm{mg}^{-1}$ protein, respectively; values are the means \pm SEM from experiments performed using microsomes obtained from 5 different preparations. pNPH, p-nitrophenol hydroxylase; $\mathrm{CoH}$, coumarin hydroxylase; EROD, ethoxyresorufin O-deethylase activity; MROD, methoxyresorufin O-demethylase activity; PROD, pentoxyresorufin O-depentylase activity; BROD, benzyloxyresorufin O-debenzylase activity; ErD, erythromycin demethylase activity. 
Table 2. Kinetic constants for PF9601N metabolism by mouse and human liver microsomal preparations.

\begin{tabular}{|c|c|c|c|c|}
\hline $\begin{array}{l}\text { Metabolite } \\
\text { formed }\end{array}$ & $\begin{array}{c}\text { Liver } \\
\text { microsomes } \\
\text { preparations }\end{array}$ & $\mathrm{K}_{m}$ & $\begin{array}{l}\mathrm{nmol}^{1} \mathrm{~h}^{-} \\
{ }^{1} \mathrm{mg}^{1} \\
\text { protein }\end{array}$ & $\mathrm{CL}_{\mathrm{I}}$ \\
\hline FA72 & mouse & $37.0 \pm 4.8$ & $26.0 \pm 1.1$ & 0.7 \\
\hline FA72 & $\begin{array}{l}\text { pre-treated } \\
\text { mouse* }\end{array}$ & $34.2 \pm 5.0$ & $20.1 \pm 0.9$ & 0.6 \\
\hline FA72 & human & $11.0 \pm 2.2$ & $10.0 \pm 0.4$ & 0.9 \\
\hline
\end{tabular}

* Pre-treated for 4days with PF9601N (10 mg x Kg i.p., daily); data are means from experiments performed from 5 different preparations. The intrinsic clearance $\left(\mathrm{CL}_{\mathrm{I}}\right)$ was calculated as $\mathrm{Vmax} / \mathrm{Km}$ ratio for each group of animals.

\section{Kinetic analysis of $\boldsymbol{l}$-deprenyl CYP-dependent metabolism by C57BL/6 mice liver microsomes}

A preliminary assay of $l$-deprenyl $\mathrm{N}$-dealkylation by mice liver microsomes, gave rise to the primary metabolites $l$-methamphetamine and $l$ - nordeprenyl, the amount of products formed increased linearly with time up to $45 \mathrm{~min}$ and the initial rates were proportional to the amount of microsomal protein added up to $1 \mathrm{mg} \mathrm{x} \mathrm{ml}^{-1}$. The formation of low amounts of the secondary metabolite, $l$-amphetamine, was also evident.

Kinetic analysis of $l$-deprenyl $\mathrm{N}$ dealkylation rates indicated that at all the concentrations of $l$-deprenyl tested, $l$ methamphetamine turned out to be the major metabolite formed, its concentration in the assay mixture being about 1.5-2.0 fold greater than that of $l$-nordeprenyl. The kinetic analysis of $l$ deprenyl metabolism data suggests that for both $\mathrm{N}$-dealkylation reactions at least two components -one characterized by low and the other by high affinity- were describing substrate concentration vs. metabolite formation rate relationship. Accordingly, as shown in the inset of Figure 5, biphasic Eadie-Hofstee plots were obtained (27).

As depicted in Table 3, the high affinity component $\left(\mathrm{Km}_{1}\right)$ for both $l$-nordeprenyl and $\mathrm{l}$ methamphetamine formation had similar $\mathrm{Km}$ values. Also the low affinity $\left(\mathrm{Km}_{2}\right)$ components had similar apparent $\mathrm{Km}$ values, but of about one order of magnitude higher than those of the high affinity component.

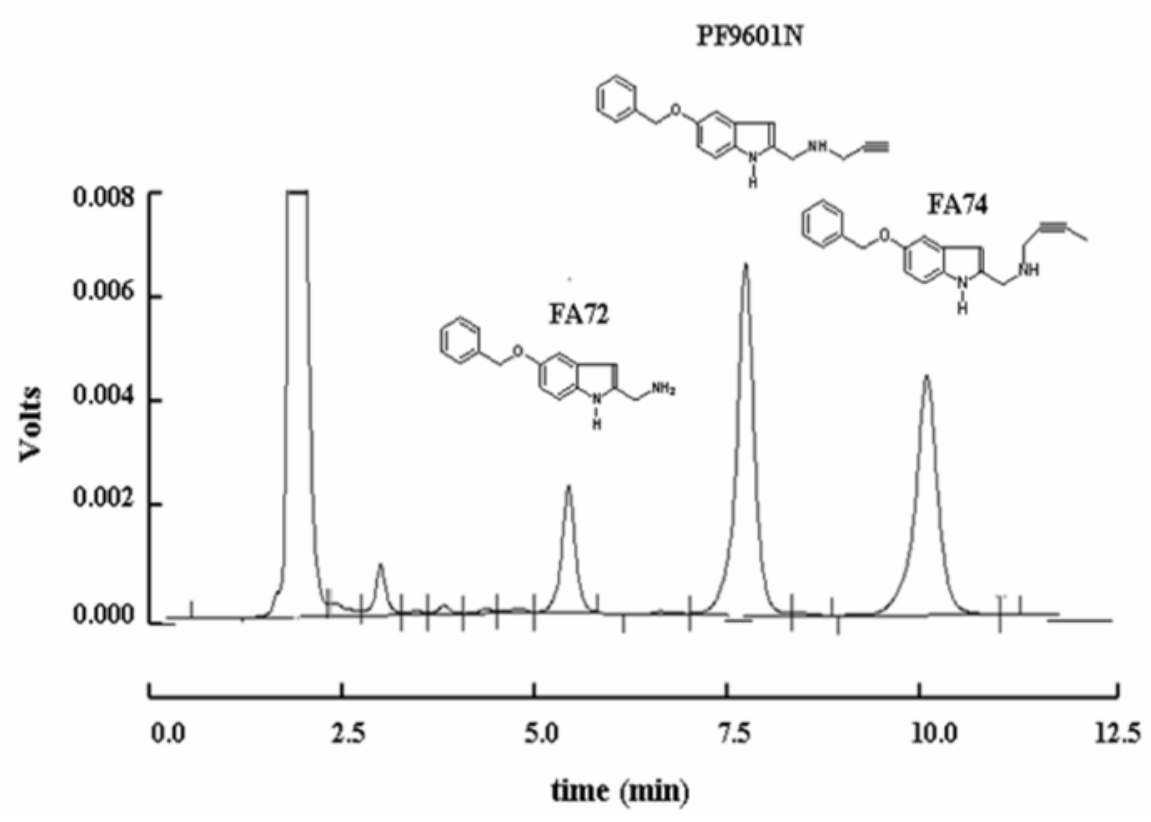

Figure 2. Typical HPLC-UV chromatogram of the ethylacetate extract of reaction mixture after incubation of PF9601N with mouse liver microsomes. HPLC analysis was performed on a C18 capillary column at a flow rate of $1 \mathrm{ml} \mathrm{x} \mathrm{min}^{-1}$. The mobile phase consisted of $10 \mathrm{mM} \mathrm{KH}_{2} \mathrm{PO}_{4} / \mathrm{CH}_{3} \mathrm{CN} / \mathrm{CH}_{3} \mathrm{OH}(60: 35: 5)$, $\mathrm{pH}$ 2. Ultraviolet detector was set at $270 \mathrm{~nm}$. 


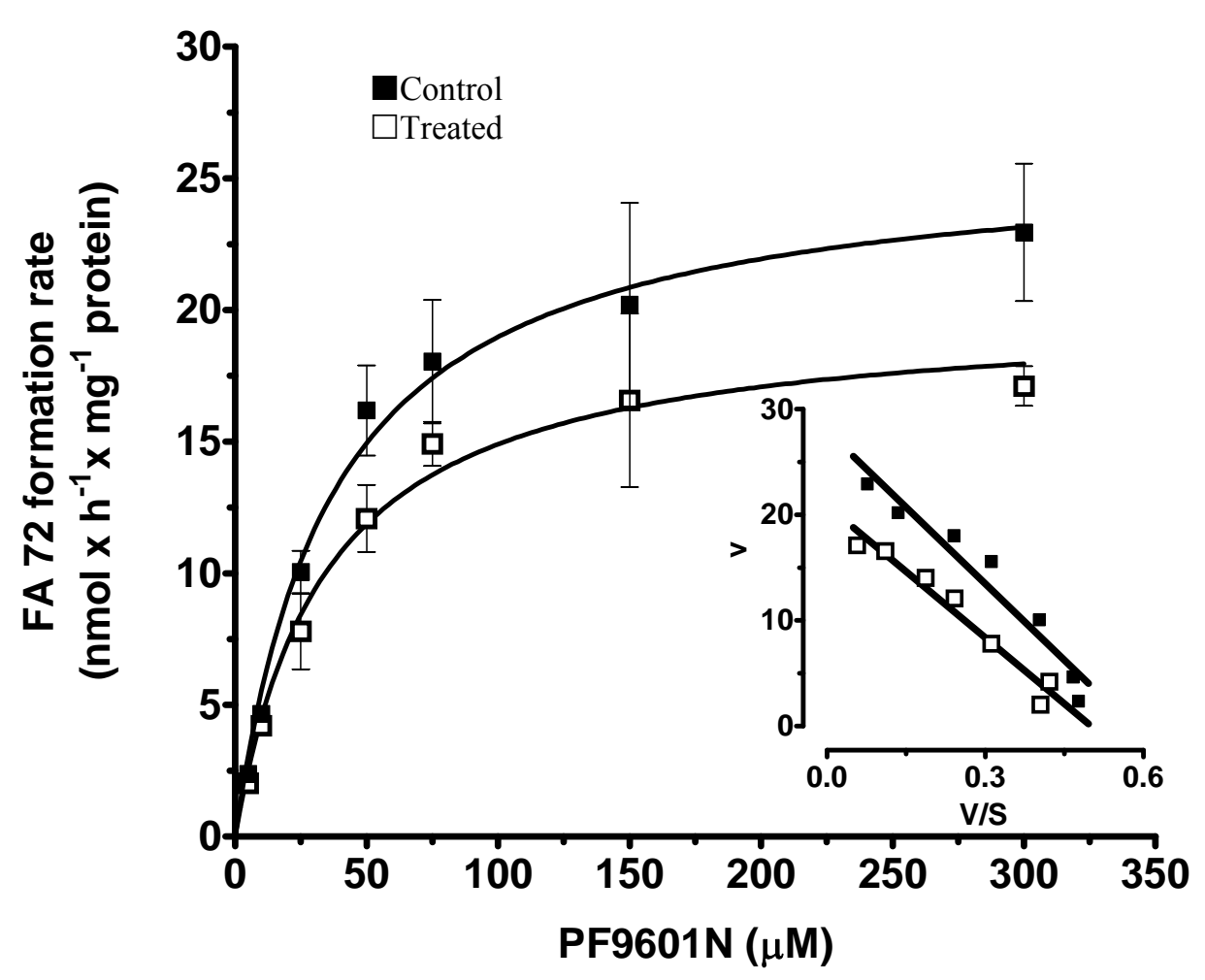

Figure 3. Kinetic analysis of FA72 formation rate by liver microsomes prepared from control and in vivo PF9601N treated mice. Data fitting was performed according to the Michaelis-Menten equation, while the inset shows the EadieHofstee plots of the same data. Data refers to the mean \pm SEM, derived from five different microsomal preparations.

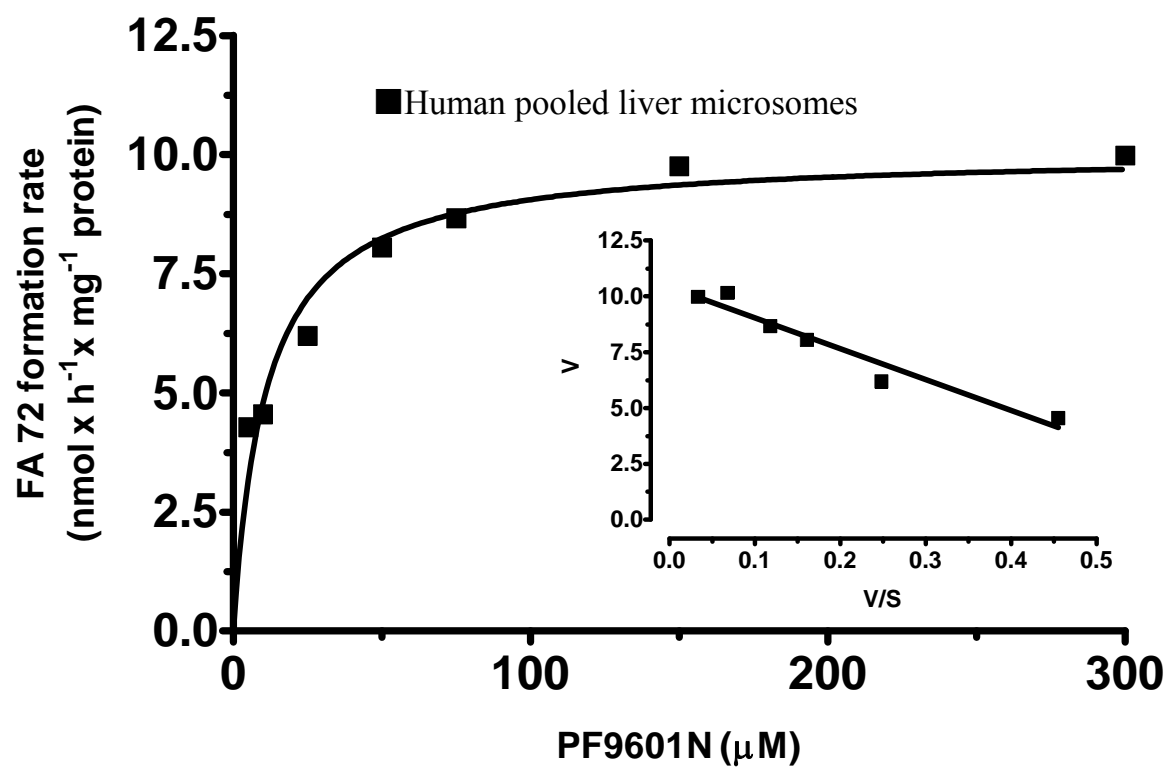

Figure 4. Kinetic analysis of FA72 formation in human pooled liver microsomes. Fitting of data from three different microsomal preparations was performed according to the Michaelis-Menten equation, while the inset shows the EadieHofstee plot of the same data. Data are reported as mean \pm SEM. 
Table 3. Kinetic constants for l-deprenyl metabolism by mouse liver microsomal preparations.

\begin{tabular}{|c|c|c|c|c|c|c|}
\hline $\begin{array}{l}\text { Metabolite } \\
\text { formed }\end{array}$ & $\mathrm{K}_{m 1}$ & $\mathrm{~K}_{m 2}$ & $\operatorname{Vmax}_{1}$ & $\mathrm{Vmax}_{2}$ & $\mathrm{CL}_{\mathrm{I} 1}$ & $\mathrm{CL}_{\mathrm{I} 2}$ \\
\hline & \multicolumn{2}{|c|}{$\mu \mathrm{M}$} & $\operatorname{nmol} \times h^{-1} x$ & $\mathrm{mg}^{1}$ protein & $\mathrm{h}^{-1}$ & $\mathrm{~h}^{-1}$ \\
\hline Methamphetamine & $23.9 \pm 7.3$ & $443.7 \pm 1.7$ & $254.8 \pm 6.2$ & $995.4 \pm 1.1$ & 10.7 & 2.2 \\
\hline Nordeprenyl & $14.6 \pm 4.2$ & $518.7 \pm 1.1$ & $123.60 \pm 2.0$ & $912.0 \pm 8.6$ & 8.5 & 1.7 \\
\hline
\end{tabular}

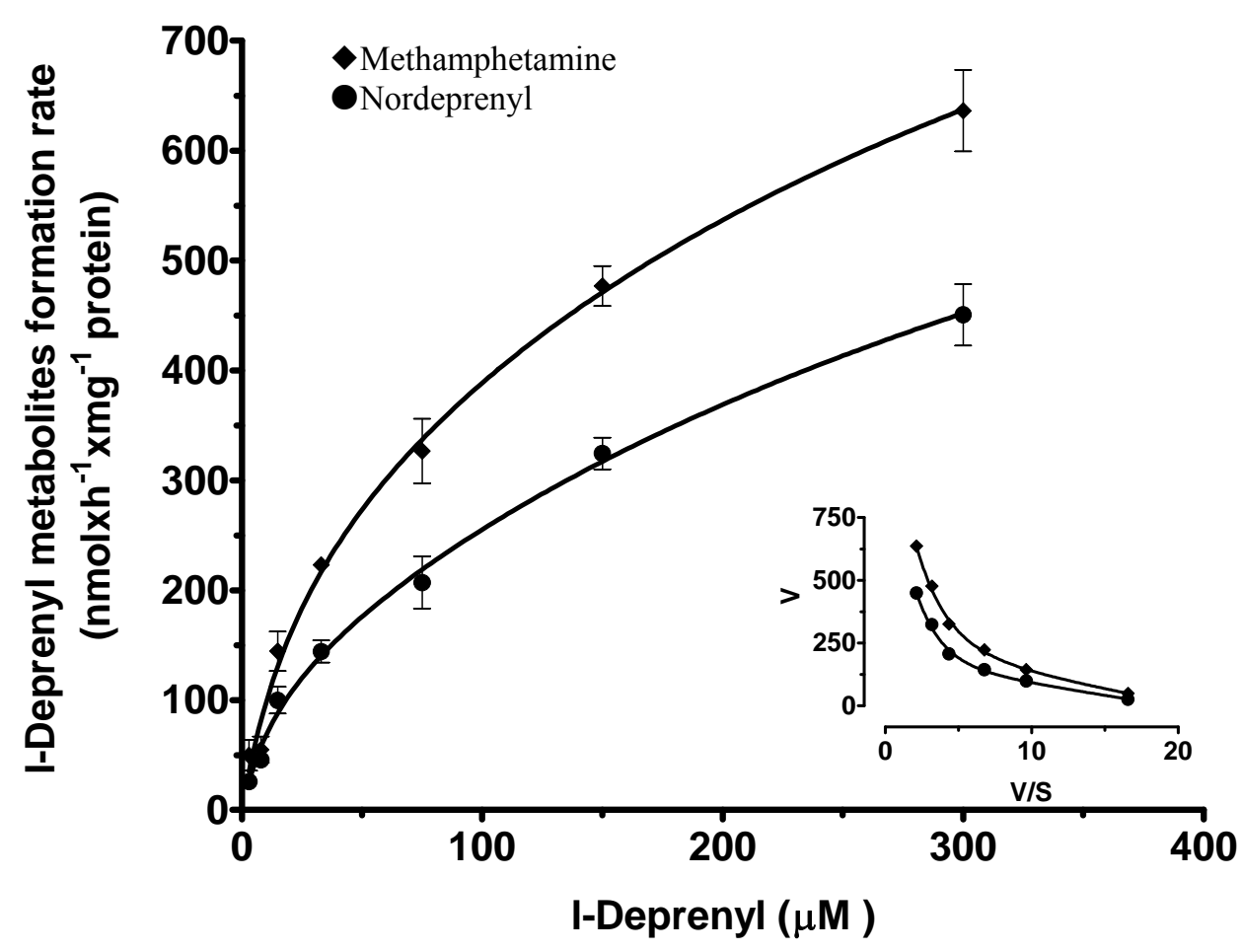

Figure 5. Kinetic analysis of methamphetamine and nordeprenyl formation rate by C57BL/6 mice liver microsomes incubated with $l$-deprenyl. Data fitting were performed according to the Michaelis-Menten equation, while the inset shows the Eadie-Hofstee plots of the same data. Data refer to the mean $\pm \mathrm{SEM}$, derived from five different microsomal preparations.

As to the low affinity component, Vmax value for l-methamphetamine formation of the high affinity component $\left(\mathrm{Vmax}_{1}\right)$ was about two fold higher than that for the formation of l-nordeprenyl. The ratio $\mathrm{Vmax} / \mathrm{Km}$, as an index of intrinsic clearance $\left(\mathrm{CL}_{\mathrm{I}}\right)$, for both metabolites was one order of magnitude higher for the high affinity component $\left(\mathrm{Km}_{1}\right)$ as compared to that for the low affinity component $\left(\mathrm{Km}_{2}\right)$. This suggests that the high affinity component is the major determinant of $l$ deprenyl N-dealkylation oxidation by mice liver microsomes.

\section{Inhibition of PF9601N metabolism by mice and human liver microsomes}

In order to identify CYP isozymes involved in PF9601N N-dealkylation, an inhibition study was performed by incubating mice or human liver microsomes with $80 \mu \mathrm{M}$ PF9601N (2 times the $K_{\mathrm{m}}$ concentration) in presence of specific inhibitors of some CYP isoenzymes. 8Methoxypsoralen, was used to inhibit mouse CYP2A5, closely related to human CYP2A6 (21), whilst 4-methylpyrazole and ketoconazole were used to inhibit mouse CYP2E1 and 3A isoforms, respectively (22-23). $\quad \alpha$-Naphthoflavone, 
sulfaphenazole, quinidine, and secobarbital were used to inhibit specifically CYPs $1 \mathrm{~A}, 2 \mathrm{C}, 2 \mathrm{D}$, and $2 \mathrm{~B}$, respectively (24-25-26).

As shown in Figure 6, only ketoconazole promoted a significant inhibition of about $35 \%$ of PF9601N N-dealkylation. CYP-dependent testosterone hydroxylase activities were also tested in presence of $80 \mu \mathrm{M}$ PF9601N. As shown in Figure 7, PF9601N significantly inhibited the formation of $6 \beta$-hydroxytestosterone, marker of CYP3A activity, by about $78 \%$ as compared to control values. Furthermore the $30 \%$ inhibition of $15 \beta$ - hydroxytestosterone formation, catalysed by CYP3A confirmed the previous data (28). The inhibition study performed on human liver microsomes showed that, as observed in mouse liver microsomal preparations, only ketoconazole significantly inhibited by about 30\% PF9601N Ndealkylation rate (Figure 8).

\section{DISCUSSION}

Acetylenic compounds, including some MAO inhibitors, have been proven to affect CYP activities and it has been suggested that they interact with other drugs by inhibiting CYP isoenzymes (29). This can have important clinical consequences, since CYPs inactivation often leads to severe and long-lasting impairment of metabolic drug clearance and clinically meaningful drug-drug interactions (30).

In the present study, the 4-days treatment of C57BL/6 mice with a novel acetylenic MAO-B inhibitor, PF9601N, did not modify cytochrome P450 and $b_{5}$ content, and did not change NADPHCYP-reductase and CYP2E1, 2A5, 1A1, 2B, 3A activities. Furthermore, CYP-dependent metabolism of PF9601N by liver microsomes from either control or treated mice gave rise only to the formation of the N-dealkylated metabolite, FA72, identified either by HPLC retention time and MS analysis. Microsomal preparations, when tested for PF9601N N-dealkylation, at various substrate concentrations, exhibited a simple hyperbolic kinetic behavior which was confirmed by monophasic Eadie-Hofstee plots from treated and control mice.

These results indicate that PF9601N does not affect its own metabolism. This is contrary to what is known for other MAOIs, such as tranylcypromine, phenelezine and moclobemide (31). Moreover, we have previously shown that a 3-days treatment of $\mathrm{C} 57 \mathrm{BL} / 6$ mice with $l$ deprenyl caused a significant decrease in liver microsomal CYP content as well as pNPH activity (12).

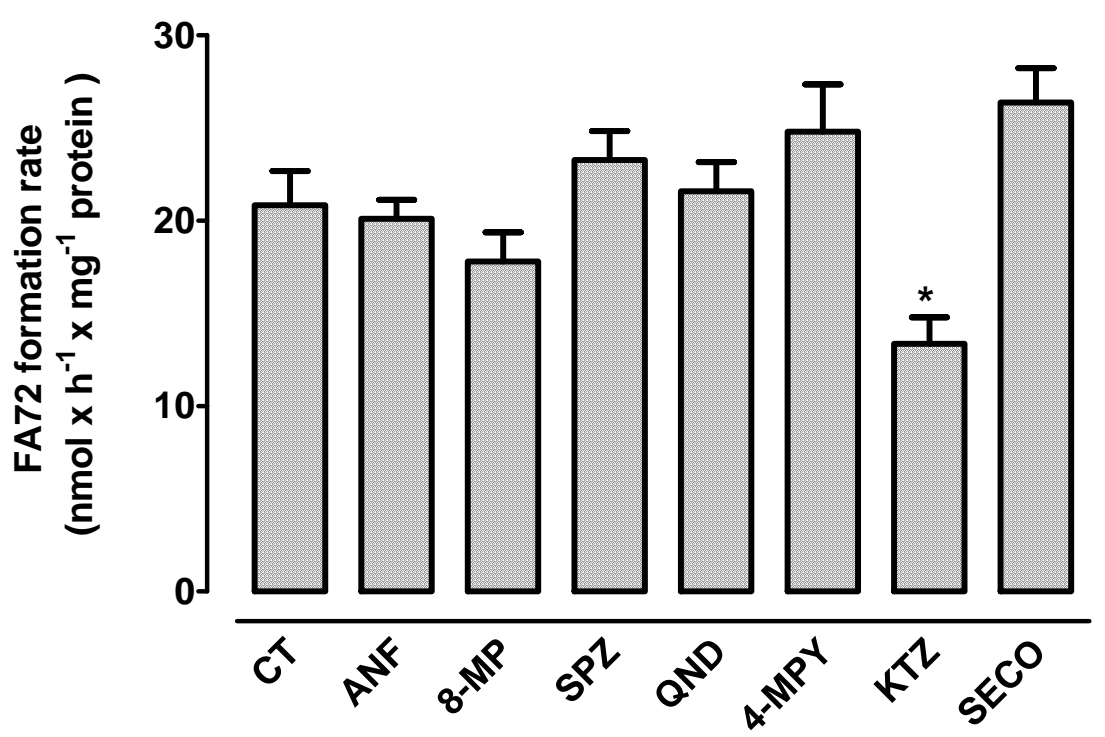

Figure 6. Effects of $\alpha$-naphthoflavone (ANF), 8-methoxypsoralen (8-MP), sulfaphenazole (SPZ), quinidine (QND), 4methylpyrazole (4-MPY), ketoconazole (KTZ) and secobarbital (SECO) on FA72 formation rate. PF9601N (80 $\mu \mathrm{M})$ was incubated with $\mathrm{C} 57 \mathrm{BL} / 6$ mouse liver microsomes at $37^{\circ} \mathrm{C}$ for $30 \mathrm{~min}$ in presence $50 \mu \mathrm{M}$ inhibitor. Data are the means \pm SEM (bars) from five different microsomal preparations. The comparison between metabolite formation in absence (CT) and in presence of inhibitor was performed by Student $t$ test; ${ }^{*} \mathrm{p}<0.05$. 


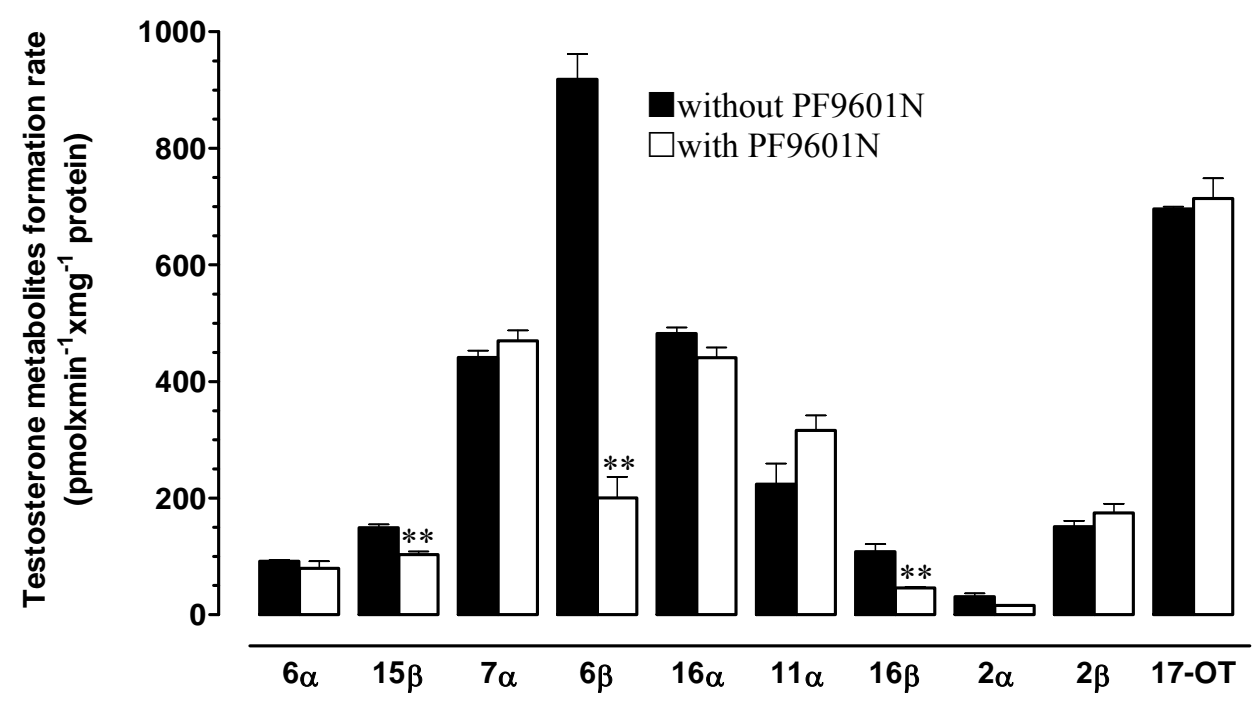

Figure 7. Testosterone hydroxylase activity by C57BL/6 microsomes. Data are means \pm SEM (bars) of five liver microsomal preparations. Incubations were carried out at $37^{\circ} \mathrm{C}$ for $30 \mathrm{~min}$ with $1 \mathrm{mg} \mathrm{x} \mathrm{ml} \mathrm{m}^{-1}$ microsomal protein. $6 \alpha / \beta$, $6 \alpha / \beta$-hydroxytestosterone; $6 \beta, 15 \beta, 15 \beta$-hydroxytestosterone; $7 \alpha, 7 \alpha$-hydroxytestosterone, 16 $\alpha / \beta, 16 \alpha / \beta$ hydroxytestosterone; $11 \alpha, 11 \alpha$-hydroxytestosterone; $2 \alpha / \beta, 2 \alpha / \beta$-hydroxytestosterone and 17-OT, androst-4-ene-3,17dione were detected. The comparison between metabolite formation rate in absence and in presence of PF9601N was performed by using Student $t$ test; ** $\mathrm{p}<0.01$.

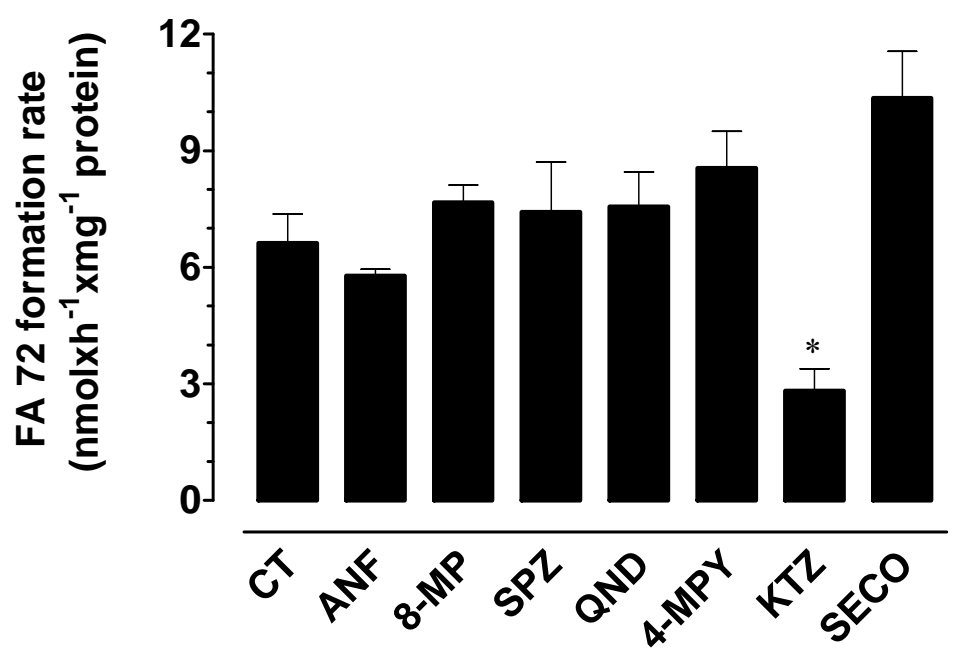

Figure 8. Effects of $\alpha$-naphthoflavone (ANF), 8-methoxypsoralen (8-MP), sulfaphenazole (SPZ), quinidine (QND), 4methylpyrazole (4-MPY), ketoconazole (KTZ) and secobarbital (SECO) on FA72 formation rate. PF9601N (80 $\mu$ M) was incubated with human pooled liver microsomes at $37^{\circ} \mathrm{C}$ for $1 \mathrm{~h}$ in presence of $50 \mu \mathrm{M}$ of inhibitor. The experiments were performed using three different microsomal preparations. The comparison between metabolite formation rate in absence (CT) and in presence of inhibitor was performed by Student $t$ test; ${ }^{*} \mathrm{p}<0.05$.

In the present study, the kinetic analysis of $l$ deprenyl N-dealkylation by mouse liver microsomes gave rise to a biphasic Eadie-Hofstee plot thus indicating that at least 2 or more enzymes catalyse the formation of methamphetamine and nordeprenyl. The kinetic costants, reported in Table 3, underline the presence of both a high and a low affinity component in the formation of l-deprenyl derivatives. Moreover, even if the apparent $\mathrm{Km}$ 
for the high affinity component $\left(\mathrm{Km}_{1}\right)$ of both methamphetamine and nordeprenyl formation was close to the values for PF9601N metabolism, a great difference was observed in the apparent Vmax values that were one order of magnitude higher for both metabolites of l-deprenyl as compared to that of FA72. This gave rise to a much higher (by one order of magnitude) intrinsic clearance of l-deprenyl (for the high affinity component, $\mathrm{CL}_{\mathrm{II}}$ ) as compared to that of PF9601N.

The high intrinsic clearance observed for l-deprenyl in mice is in agreement with what has been observed in humans (32), wherein l-deprenyl has a very low oral bioavailability $(10 \%)$ as the result of extensive hepatic first-pass metabolism (3). The high intrinsic clearance of l-deprenyl in humans, indeed, makes it difficult to achieve clinically effective plasma concentrations following oral doses. For these reasons, transdermal l-deprenyl formulations have been developed recently, which, give rise to persistent (minimal peak-trough fluctuations), high plasma levels of the parent compound, with high amounts of the drug being delivered to the brain and a low metabolite production (33-34).

As compared with l-deprenyl, PF9601N, has a lower intrinsic clearance. Neither the new drug influences CYP contents and related monoxygenase activities. This suggests a higher metabolic stability and a lower chance to give rise to drug-drug interactions for $\mathrm{PF} 9061 \mathrm{~N}$ as compared with l-deprenyl. PF9601N, therefore, may be a suitable candidate for development an alternative to l-deprenyl. Moreover, similarly to what has been observed in mouse, CYPdependent metabolism of PF9601N by human liver microsomes gave rise to a linear EadieHofstee plot suggesting the involvement of only one isozyme, with $\mathrm{Km}$ and Vmax values very close to the values observed in the mouse (Table 2). In contrast, the apparent $\mathrm{Km}$ values detected with $l$-deprenyl in mouse were quite different from the values given by human liver microsomes (35-36). This suggests that the use of mouse liver microsomes to predict $l$-deprenyl metabolism in humans is inconsistent. The inhibition study performed in mouse liver microsomes showed a significant inhibition by ketoconazole only of FA72 formation, suggesting the major involvement of CYP3A in PF9601N metabolism. The role of CYP3A was confirmed by the marked inhibition of the formation of $6-\beta$ and $15-\beta-$ hydroxytestosterone derivatives. The weak inhibition of 16- $\beta$-hydroxytestosterone formation rate, however, is not indicative of the involvement of CYP2B as confirmed by the finding that secobarbital, a selective rat $2 \mathrm{~B} 1$ inhibitor, was not able to inhibit PF9601N metabolism by mouse liver microsomes (37-38). The inhibition study performed on human liver microsomes suggests the major involvement of CYP 3A family, as previously observed in mouse liver microsomes.

In conclusion these results suggest the use of PF9601N, a non amphetamine-like MAO-B inhibitor, be promoted in Parkinson's patients. Furthermore, this study indicates that the mouse is a good animal model to predict the metabolism of PF9601N in humans.

\section{ACKNOWLEDGEMENTS}

The authors are grateful to Dr. Claudio Polloni, for invaluable technical assistance. This work was realized in the framework of COST working group: D34/0003/05 and financed by Ministero degli Affari Esteri (Roma, Italy) under Law 212/92 and partially by PRIN 2003 \#2003063319.

\section{REFERENCES}

[1]. Gerlach, M., Riederer, P. and Vogt, H. Effect of adding selegiline to levodopa in early, mild Parkinson's disease. "On treatment" rather than intention to treat analysis should have been used. BMJ, 312:704-705, 1996.

[2]. The Parkinson Study Group. Effects of tocopherol and deprenyl on the progression of disability in early Parkinson`s Disease. N Engl J Med 328: 176-183, 1993.

[3]. Anttila, M., Sotaniemi, E.A., Pelkonen, O. and Rautio, A. Marked effect of liver and kidney function on the pharmacokinetics of selegiline. Clin Pharmacol Ther, 77: 54-62, 2005.

[4]. Tipton, K.F. What is it that l-deprenyl (selegiline) might do? Clinic Pharmacol Ther, 56: 781-796, 1994.

[5]. Yu, P.H., Davis, D.A., Durden, A., Barber, A., Terleckyj, I., Nicklas, W.G. and Boulton, A. Neurochemical and neuroprotective effects of some aliphatic propargylamines: new selective nonamphetamine-like monoamine oxidase B inhibitors. J Neurochem 62: 697-704, 1994.

[6]. Lees, A.J. Comparison of therapeutic effects and mortality data of levodopa and levodopa combined with selegiline in patients with early, mild Parkinson's disease. Parkinson's Disease Research Group of the United Kingdom. BMJ, 311: 1602-1607, 1995.1

[7]. Cruces, M.A., Elorriaga, C. and Fernández- 
Álvarez, E. Acetylenic and allenic derivatives of 2-(5-metoxyindolyl) and 2-(5hydroxyindolyl) methylamines: synthesis and in vitro evaluation as monoamine oxidase inhibitors. Eur Med Chem, 26: 33-41, 1991.

[8]. Pérez, V., Marco, J.L., Fernández-Álvarez, E. and Unzeta, M. Relevance of benzyloxy group in 2-indolyl methylamines in the selective MAO-B inhibition. Br J Pharmacol, 127: 869876, 1999.

[9]. Lamensdorf, I., Porat, S., Simantov, R. and Finberg, J.P. Effect of low-dose treatment with selegiline on dopamine transporter (DAT) expression and amphetamine-induced dopamine release in vivo. Br J Pharmacol, 126: 997-1002, 1999.

[10]. Prat, G., Pérez, V., Rubio, A., Casas, M. and Unzeta, M. The novel type MAO B inhibitor PF9601N enhances the duration of L-DOPAinduced contralateral turning on 6hydroxydopamine lesioned rats. J Neural Transm, 107 : 409-417, 2000.

[11]. Sanz, E., Romera, M., Belyk, L, Marco, J.I. and Unzeta, M. Indolalkylamines derivatives as antioxidant and neuroprotective agents in on experimental model of Parkinson's disease. Med Sci Monit, 10: 477-484, 2004.

[12]. Valoti, M., Fusi, F., Frosini, M., Pessina, F., Tipton, K.F. and Sgaragli, G.P. Cytochrome P450-dependent N-dealkylation of L-deprenyl in C57BL mouse liver microsomes: effects of in vivo pretreatment with ethanol, phenobarbital, beta-naphthoflavone and Ldeprenyl. Eur J Pharmacol 39: 199-206, 2000.

[13]. Omura, T. and Sato, R. The carbon monoxidebinding pigment of liver microsomes. I. Evidence for its hemoprotein nature. J Biol Chem 239: 2370-2378, 1964.

[14]. Masters, B.S.S., William, C.H., Kamin, H. The preparation and properties of microsomal NADPH-cytochrome c reductase from pig liver. In R.W. Estabrook, E.E. Pulman (eds) Methods in Enzymology, vol. 10 . Academy Press, New York, NY, pp 565-573, 1967.

[15]. Amato, G., Longo, V., Mazzacaro, A. and Gervasi, P.G. Chlorzoxazone 6-hydroxylase and p-nitrophenol hydroxylase as the most suitable activities for assaying cytochrome P450 2E1 in cynomolgus monkey liver. Drug Metab Dispos, 26: 483-489, 1998.

[16]. Tu, Y.Y. and Yang, C.S. High-affinity nitrosamine dealkylase system in rat liver microsomes and its induction by fasting. Cancer Res 43: 623-629, 1983.

[17]. Krijgsheld, K.R. and Gram, T.E. Selective induction of renal microsomal cytochrome P450-linked monooxygenases by 1,1dichloroethylene in mice. Biochem Pharmacol, 33: 1951-1956, 1984.

[18]. Ko, I.Y., Park, S.S., Song, B.J., Patten, C.,
Tan, Y.Z., Hah, Y.C., Yang, C.S. and Gelboin H.V. Monoclonal antibodies to ethanolinduced rat liver cytochrome P-450 that metabolizes aniline and nitrosamines. Cancer Res, 47: 3101-3109, 1987.

[19]. Reinke, L.A. and Moyer, M.J. p-Nitrophenol hydroxylation. A microsomal oxidation which highly inducible by ethanol. Drug Metab Dispos 13: 548-552, 1985.

[20]. Dragoni, S., Bellik, L., Frosini, M., Sgaragli, G., Marini, S., Gervasi, P.G. and Valoti, M. 1Deprenyl metabolism by the cytochrome P450 system in monkey (Cercopithecus aethiops) liver microsomes. Xenobiotica, 33: 181-195, 2003.

[21]. Takeuchi, H., Saoo, K., Matsuda, Y., Yokohira, M., Yamakawa, K., Zeng, Y., Miyazaki, M., Fujieda, M., Kamataki, T. and Imaida, K. Dose dependent inhibitory effects of dietary 8-methoxypsoralen on NNKinduced lung tumorigenesis in female $\mathrm{A} / \mathrm{J}$ mice. Cancer Lett, 234: 232-238, 2006.

[22]. Newton, D.J., Wang, R.W. and Lu, A.Y.H. Cytochrome P450 inhibitors: evaluation of specificities in the in vitro metabolism of therapeutic agents by human liver microsomes. Drug Metab Dispos, 23: 154-158, 1995.

[23]. Reidy, G.F., Mehta, I. and Murray, M. Inhibition of oxidative drug metabolism by orphenadrine: in vitro and in vivo evidence for isozyme-specific, complexation of cytochrome P-450 and inhibitor kinetics. Mol Pharmacol, 35: 736-774, 1989.

[24]. Lakshmi, V.M., Zenser, T.V. and Davis, B.B. Rat liver cytochrome $\mathrm{P} 450$ metabolism of Nacetylbenzidine and N,N'-diacetylbenzidine. Drug Metab Dispos, 25: 481-488, 1997.

[25]. Chung, H.J., Choi, Y.H., Kim, S.H. and Lee M.G. Effects of enzyme inducers and inhibitors on the pharmacokinetics of intravenous ipriflavone in rats. J Pharm Pharmacol, 58: 449-457, 2006.

[26]. Lewis, D.F., Eddershaw, P.J., Dickins, M., Tarbit, M.H and, Goldfarb, P.S. Structural determinants of cytochrome P450 substrate specificity, binding affinity and catalytic rate. Chem Biol Interact, 115: 175-199, 1998.

[27]. Hutzler J.M., Tracy T.S. Atypical kinetic profiles in drug metabolism reactions. Drug Metab Dispos, 30:355-362, 2002.

[28]. Hernandez, J.P., Chapman, L.M., Kretschmer, X.C. and Baldwin, W.S. Gender-specific induction of cytochrome P450s in nonylphenol-treated FVB/NJ mice. Toxicol Appl Pharmacol, 216: 186-196, 2006.

[29]. Baker, G.B., Urichuk, L.J., McKenna, K.F. and Kennedy, S.H. Metabolism of monoamine oxidase inhibitors. Cell Mol Neurobiol, 19: 411-426, 1999.

[30]. Lin, J.H. and Lu, A.Y. Inhibition and induction 
of cytochrome $\mathrm{P} 450$ and the clinical implications. Clin Pharmacokinet, 35: 361390, 1998.

[31]. Mallinger, A.G and Smith, E. Pharmacokinetics of monoamine oxidase inhibitors. Psychopharmacol Bull, 27: 493502, 1991.

[32]. Elkashef, A., Fudala, P.J., Gorgon, L., Li, S.H., Kahn, R., Chiang, N., Vocci, F., Collins, J., Jones, K., Boardman, K. and Sather M. Double-blind, placebo-controlled trial of selegiline transdermal system (STS) for the treatment of cocaine dependence. Drug Alcohol Depend, 85: 191-197, 2006.

[33]. Barrett J.S., Hochadel, T.J., Morales, R.J., Rohatagi, S., DeWitt, K.E., Watson, S.K. and DiSanto, A.R. Pharmacokinetics and Safety of a Selegiline Transdermal System Relative to Single-Dose Oral Administration in the Elderly. Am J Ther, 3: 688-698, 1996.

[34]. Wecker, L., James, S., Copeland, N. and Pacheco, M.A. Transdermal selegiline: targeted effects on monoamine oxidases in the brain. Biol Psychiatry 54: 1099-1104, 2003.

[35]. Salonen, J.S., Nyman, L., Boobis, A.R., Edwards, R.J., Watts, P., Lake, B.G., Price, R.J., Renwick, A.B., Gomez-Lechon, M.J., Castell, J.V., Ingelman-Sundberg, M., Hidestrand, M., Guillouzo, A., Corcos, L., Goldfarb, P.S., Lewis, D.F., Taavitsainen, P. and Pelkonen, O. Comparative studies on the cytochrome p450-associated metabolism and interaction potential of selegiline between human liver-derived in vitro systems. Drug Metab Dispos 31: 1093-1102, 2003.

[36]. Taavitsainen, P., Anttila, M., Nyman, L., Karnani, H., Salonen and J.S., Pelkonen, O. Selegiline metabolism and cytochrome P450 enzymes: in vitro study in human liver microsomes. Pharmacol Toxicol 86: 215-221, 2000.

[37]. Waxman, D.J. and Walsh, C. Phenobarbitalinduced rat liver cytochrome P-450. Purification and characterization of two closely related isozymic forms. J Biol Chem 257: 10446-10457, 1982.

[38]. Lunetta, J.M., Sugiyama, K. and Correia, M.A. Secobarbital-mediated inactivation of rat liver cytochrome P-450b: a mechanistic reappraisal. Mol Pharmacol, 35: 10-17, 1989. 